\title{
Pemilihan Supplier dan Alokasi Order Asam Jawa Dengan Menggunakan Metode Fuzzy Ahp Dan Goal Programing
}

\author{
Sebro Mulasi \\ Jurusan Teknik Industri, Fakutas Teknik, Universitas Muhammadiyah Malang \\ Jl. Raya Tlogomas 246 Malang 65144 Jawa Timur \\ Surel: broodoank@hotmail.co.id
}

\begin{abstract}
Supplier selection process was become important consideration to improve the efficiency of procurement department because the raw material cost could reach $70 \%$ of product cost. The supplier selection process was multi-criteria problem involving qualitative and quantitative factors. The company often experienced shortage of good quality tamarind with a cheap price which companies often reject order from customers. Therefore the company should make a selective supplier selection and allocation of orders for optimum results by considering both qualitative and quantitative factors that can minimize the cost of purchase, maximizing the weight of suppliers and minimize the total defect order. This research will integrate supplier weight from Fuzzy Analytic Hierarchy Process and Goal Programming model for the final decision of supplier selection and allocation of orders. By running goal programming model give solution better than order allocation current model where it could reduce total cost of purchasing at $R p 130.000 .000$ to $R p 127.700 .000$ and reduce total of defect order at $4 \%$ to $0,87 \%$.
\end{abstract}

Keywords: tamarind, suplier selection, supplier weight, fuzzy analytical hierarki process, goal programing included.

\begin{abstract}
Abstrak
Pemilihan supplier merupakan faktor pertimbangan penting untuk meningkatkan efisiensi bagian penggadaan bahan baku, dimana biaya untuk pembelian bahan baku dapat mencapai $70 \%$ dari biaya penjualan produk. Pemilihan supplier sering menjadi pemasalahan multikriteria yang melibatkan faktor kualitatif dan kuantitatif. Masalah di perusahaan adalah sering mengalami kekurangan pasokan asam jawa yang kualitasnya baik dengan harga yang cukup murah, sehingga perusahaan sering menolak permintaan yang datang. Perusahaan perlu melakukan pemilihan supplier asam jawa secara selektif dan pengalokasian pesanan agar optimal dengan mempertimbangkan faktor kualitatif dan kuantitatif. Tahapan pengolahan data dimulai dengan menentukan bobot pemasok dari hasil Fuzzy Analytical Hierarki Process (F-AHP). Tahap 2 menggunakan Goal Programing untuk menentukan keputusan kahir pemilihan supplier beserta alokasi ordernya. Model Goal Programing diformulasikan untuk mencapai tiga fungsi tujuan yaitu minimasi biaya pembelian, maksimasi bobot supplier dan minimasi total order cacat. Model goal programming memberikan solusi yang lebih baik daripada alokasi order saat ini. Total biaya pembelian dapt berkurang dari $R p 130.000 .000$ menjadi $R p$ 127.700.000 dan mengurangi total pesanan cacat pada 4\% ke 0,87\%.
\end{abstract}

Kata kunci: asam jawa, Pemilihan supplier, bobot pemasok, fuzzy analytical hierarki process, goal programing.

\section{Pendahuluan}

Supplier merupakan faktor penting dalam proses pengadaan bahan baku dan berpengaruh dalam eksistensi suatu perusahaan, kriteria pemilihan adalah salah satu hal penting dalam pemilihan supllier, kriteria yang digunakan tentunya harus mencerminkan strategi supllychain maupun dari karakteristik dari item yang dipasok. 
Secara umum perusahaan menggunakan kriteria-kriteria dasar seperti kualitas barang yang ditawarkan, harga dan ketepatan waktu pengiriman pemilihan supplier sendiri menjadi sebuah hal yang krusial.

CV. MANDIRI merupakan salah satu perusahaan bergerak dibidang agribisnis, dimana perusahaan ini menawarkan produk-produk hasil bumi, salah satunya yaitu asam jawa. Perusahaan memasarkan asam jawa nya di daerah Kalimantan Barat terutama Pontianak, sambas dan sekitarnya. Selama ini CV. MANDIRI telah memiliki beberapa pemasok, tetapi meskipun memiliki beberapa pemasok perusahaan masih sering kekurangan pasokan asam jawa. Kekurangan pasokan dapat disebebkan oleh beberapa hal, antara lain adalah kualitas dan harga asam jawa sendiri tidak sesuai dengan yang ditetapkan dan jumlah asam yang dipesan tidak sesuai yang dijanjikan. sehingga perusahaan kadang harus menolak permintaan yang datang.

Tujuan dari studi ini adalah dilakukan penyaranan untuk pemilihan pemasok asam jawa secara selektif dengan mempertimbangkan bobot kriteria seperti harga yang relatif murah, kualitas yang baik dan mampu memasok perusahaan. Selain itu diperlukan pengalokasian pesanan untuk meminimasi resiko pembengkakan biaya pembelian dan meminimasi cacat pada pasokan. Untuk mewujudkan tujuan diatas makan dalam penelitian memilih untuk menggunakan integrasi dari metode yaitu Fuzzy Analytical Hierarki Proses ( F-AHP ), dan Goal Programing. Dimana F-AHP digunakan untuk penilaian alternatif pemasok berdasarkan sejumlah kriteria dan subkriteria[1, 2]. Dimana hasil dari penilaian akan menjadi koefisien fungsi tujuan maksimasi bobot dari alternatif pemasok pada model Goal Programing.

\section{Metode Penelitian}

Objek dalam studi penelitian ini adalah supplier asam jawa. Dimana pada penelitian ini akan dilakukan pemilihan dan pengalokasian order dengan mempertimbangkan beberapa faktor yaitu kriteria, subkriteria dan alternatif (supplier). Tahapan pertama dalam penelitian ini adalah menentukan tujuan, kriteria, subkriteria dan alternatif (supplier), dimana dalam menentukan ini perlu dilakukan wawancara dan diskusi dengan bagian pengadaan. Selanjutnya akan dilakukan pembuatan struktur hierarki yang terdiri dari kriteria, subkriteria dan alternatif.

Setelah diperoleh struktur hierarki, maka selanjutnya adalah menentukan nilai bobot dari setiap kriteria, subkriteria dan alternatif yaitu dengan memberikan kuisioner perbandingan berpasangan kriteria, subkriteria dan alternatif pemasok kepada bagian pengadaan. Setelah didapatkan nilai bobot, selanjutnya adalah menentukan tingkat prioritas kriteria, subkriteria dan alternatif pemasok dengan menggunakan metode FAHP[3]. Sebelum melakukan pengolahan dengan F-AHP, diperlukan perhitungan AHP untuk melakukan sebuah pengujian yaitu uji konsistensi. Untuk melakukan uji konsistensi dilakukan perbandingan berpasangan dan kemudian diolah menjadi matriks perbandingan berpasangan. Setelah selesai mendapatkan matriks perbandingan berpasangan maka selanjutnya adalah melakukan uji konsistensi, dimana jika nilai Consistency Ratio (CR) yang diperoleh kurang dari 0,1 maka dapat disimpulkan penilaian telah konsisten dan dapat dilanjutkan ketahap pengolahan F-AHP.

Tahap berikutnya adalah tahap pengolahan F-AHP yang diusulkan oleh Chang (1996), dimana pada tahap ini dibagi menjadi beberapa langkah yaitu tahap transformasi Triangular Fuzzy Number (TFN), dimana pada tahap ini dilakukan perubahan bilangan AHP kedalam bilangan fuzzy. Tahap selanjutnya adalah tahap perhitungan nilai sintesis fuzzy (Si), untuk mendapatkan nilai sintesis dapat menggunakan persamaan berikut: 
$S i=\sum_{j=1}^{m} M_{g i}^{j} x\left[\sum_{i=j}^{n} \sum_{j=1}^{m} M_{g i}^{j}\right]$

Dimana :

$\mathrm{Si} \quad=$ nilai sintesis fuzzy

$\sum_{j=1}^{m} M_{g i}^{j}=$ menunjukkan nilai sel pada kolom yang dimulai dari kolom 1 disetiap baris matriks

$\mathrm{j}=$ kolom

$\mathrm{i} \quad=$ baris

M = bilangan triangular fuzzy number

$\mathrm{m} \quad=$ jumlah kriteria

$\mathrm{g} \quad=$ parameter $(1, \mathrm{~m}, \mathrm{u})$

Setelah dilakukan perhitungan nilai sintesis ( $\mathrm{Si})$, maka tahap selanjutnya adalah tahap perhitungan nilai vektor (V), nilai kordinat defuzzifikasi (d') dan bobot (W'). Untuk mendapatkan nilai vektor dapat menggunakan persamaan berikut:

$$
\mathrm{V}=(\mathrm{M} 2 \geq \mathrm{M} 1)=\left\{\begin{array}{cl}
1 ; & \text { Jika } \mathrm{m} 2 \geq \mathrm{m} 1 \\
0 ; & \text { Jika } 11 \geq \mathrm{u} 2 \\
\frac{l 1-u 2}{(m 2-u 2)-(m 1-l 1)} ; & \text { Jika kondisi lain }
\end{array}\right.
$$

Dimana :

$$
\begin{array}{ll}
\mathrm{V} & =\text { nilai vektor } \\
\mathrm{M} & =\text { matrik nilai sintesis fuzzy } \\
\mathrm{L} & =\text { nilai terendah } \\
\mathrm{m} & =\text { nilai tengah } \\
\mathrm{u} & =\text { nilai tinggi } \\
\text { sehingga diperoleh nilai kordinat }
\end{array}
$$

$\mathrm{d}^{\prime}(\mathrm{Ai})=\min \mathrm{V}(\mathrm{Si} \geq \mathrm{Sk})$

dimana :

$\mathrm{Si} \quad=$ nilai sintesis fuzzy

$\mathrm{Sk} \quad=$ nilai sintesis fuzzy yang lain

Untuk $\mathrm{k}=1,2, \ldots, \mathrm{n} ; \mathrm{k} \neq \mathrm{i}$ maka nilai vektor bobot di definisikan :

$\mathrm{W}^{\prime} \quad=\left(\mathrm{d}^{\prime}(\mathrm{A} 1), \mathrm{d}^{\prime}(\mathrm{A} 2), \ldots ., \mathrm{d}^{\prime}(\mathrm{An})\right)^{\mathrm{T}}$

Setelah mendapatkan nilai bobot (W'), maka selanjutnya memasuki tahap akhir dari pengolahan F-AHP yaitu tahap normalisasi bobot (W). Untuk melakukan normalisasi dapat menggunakan persamaan berikut:

$$
\mathrm{W}^{\prime}=\left(\mathrm{d}^{\prime}(\mathrm{A} 1), \mathrm{d}^{\prime}(\mathrm{A} 2), \ldots ., \mathrm{d}^{\prime}(\mathrm{An})\right)^{\mathrm{T}}
$$

Perumusan normalisasinya adalah :

$\mathrm{d}(\mathrm{An})=\frac{d^{1}(A n)}{\sum_{i=1}^{n} d^{1}(A n)}$

Normalisasi bobot ini akan dilakukan agar nilai dalam vektor diperbolehkan mejadi analog dan terfiri dari bilangan yang non-fuzzy[4]. Sintesis hierarki merupakan tahap untuk menghitung skor akhir tiap pemasok dengan mengalikan bobot subkriteria dan skor pemasok[5]. Berdasarkan skor akhir (bobot global) dapat ditentukan ranking pemasok mulai dari yang tertinggi sampai terendah. 
Setelah melakukan pengolahan dengan F-AHP maka dilanjutkan dengan formulasi model matematis untuk mendapatkan hasil akhir keputusan pemasok terplih dam kuantitas pesan masing-masing pemasok terpilih dengan mempertimbangkan batasan kemampuan pasok dan permintaan [6] asam jawa. Formulasi model Goal Programing untuk pemilihan pemasok sebagai berikut [7]:

\section{Variabel Keputusan}

Xij : Kuantitas order untuk pemasok-i pada priode-j

Ujt : pencapaian dibawah target dari goal ke-j pada priode ke-t

Ejt : pencapaian diatas target dari goal ke-j pada priode ke-t

\section{Parameter}

$\mathrm{Ci}$ : Harga dari pemasok-i

Wi : Bobot pemasok-i ( Dari hasil bobot global pemasok)

Vt : Value pembelian (Dari hasil generate aloksi order berdasarkan maksimasi bobot pemasok)

qi : Persentase cacat yang dipasok pemasok-i

Q : Maksimum persentase cacat yang diijinkan perusahaan

Dt : Permintaan pada priode ke-t

Si : Kapasitas pasok oleh pemasok-i

\section{Fungsi Pembatas}

$\mathrm{Xij} \leq \mathrm{Si}$
$\sum_{i=1}^{n} X i j=D t$

\section{Fungsi Prioritas tujuan / Goals}

Min $\mathrm{Z}_{1}$

$\sum_{i=1}^{n} C i . X i t+U j t-E j t$

Max Z2

$\sum_{i=1}^{n} W i . X i t+U j t-E j t=V t$

Min $\mathrm{Z}_{3}$

$\sum_{i=1}^{n} q i . X i t+U j t-E j t=Q . d t$

Dimana :

$\mathrm{Z}_{1}$ : Minimasi biaya pembelian

$\mathrm{Z}_{2}$ : Maksimasi bobot pemasok

$\mathrm{Z}_{3}$ : Minimasi prosentase cacat

Fungsi Minimasi Penyimpangan Goal

Min : $\mathrm{E}_{11}+\mathrm{U}_{21}+\mathrm{E}_{31}$ 
Berdasarkan formulasi diatas, tahap berikutnya adalah mencari solusi optimal dengan menggunakan software LINDO 6.1, dimana solusi optimal meliputi antara hasil keputusan akhir pemasok terpilih, berapa banyak kuantitas order dan apakah semua tujuan yang telah ditetapkan tercapai atau tidak sesuai target.

\section{Hasil dan Pembahasan}

Perusahaan CV MANDIRI memiliki beberapa supplier untuk memasok asam jawa, dimana supplier ini adalah para pengepul asam jawa di daerah mereka. Adapun supplier tersebut antara lain Bahruki, Toncan, UD Ikah dan Menten. Masing-masing supplier memiliki kemampuan memasok asam jawa sebesar 9 ton untuk Bahruki, 6 ton untuk Toncan, 8 ton untuk UD Ikah dan 9 ton untuk Menten. Sedangkan harga yang ditawarkan oleh masing-masing pemasok sebesar 5300/kg untuk Bahruki, 6000/kg untuk Toncan dan 5500/kg untuk UD Ikah dan Menten.

Berdasarkan hasil wawancara dan diskusi dari pihak perusahaan bagian pengadaan asam jawa diperoleh kriteria dan subkriteria yang dianggap penting dan perlu dipertimbangkan untuk digunakan sebagai dasar pemilihan supplier. Adapun kriteria dan subkriteria yaitu antara lain :

1. Harga

Harga yang dimaksud terdiri dari harga pembelian per-kilogram dan tingkat keseringan pemberian diskon oleh alternatif pemasok.

2. Kualitas

Kualitas asam jawa dapat dilihat dari tiga faktor yaitu tingkat kekeringan asam, dimana asam memiliki kandungan air yang sedikit dan tidak terlalu lembek. Selain itu dapat dilihat dari warna asam sendiri, asam jawa yang masih baru dan proses penjemuran optimal akan berwarna kuning. Terakhir kualitas asam jawa dipengaruhi oleh kemasan asam jawa itu sendiri, dimana asam jawa dengan kemasan yang jelek akan mengakibatkan asam jawa mudah dihinggapi hama/kutu pada biji asam sehingga akan membuat asam mengeras dan rusak.

3. Kapasitas/kuantitas

Kapasitas/kuantitas yang dimaksud disini ada 2 yaitu kemampuan memasok dari alternatif pemasok dan kesetabilan ketersediaan asam pada setiap musim.

4. Fleksibilitas

Dalam keriteria fleksibilitas terbagi menjadi fleksibilitas dalam perubahan jumlah pemesanan, perubahan waktu antar pengiriman asam jawa dan fleksibilitas tengang waktu pembayaran. Perubahan jumlah pemesanan yang dimaksud disini adalah jika pada suatu saat perusahaan ingin mengurangi atau menambah jumlah yang dipesan, sedangkan perubahan waktu antar pengiriman adalah dimana pada saat perusahaan belum siap menampung atau menerima kedatangan asam jawa, karena pada saat ada pengiriman asam jawa perusahaan membutuhkan tenaga kerja kuli untuk proses bongkar asam jawa.

5. Servis

Dalam kriteria servis terbagi menjadi 3 yaitu servis dalam kemudahan mendapatkan informasi mengenai asam jawa (harga terbaru, ketersediaan, dll.). selain itu ada servis mengenai kecepatan respon jika ada komplain dari perusahaan kepada alternatif pemasok. Dan yang terkahir adalah servis mengenai garansi dan klaim jika terdapat asam cacat yang melebihi ketentuan perusahaan, dalam hal ini ada beberapa perusahaan yang memberikan garansi berupa penggantian asam atau pemotongan harga/kilogram asam itu sendiri. 
Dari kriteria dan subkriteria yang telah ditetapkan diatas akan dibuat struktur hierarki. dengan menggunakan struktur hierarki akan dilakukan penilaian perbandingan berpasangan kriteria, subkriteria dan alternatif dengan cara memberikan kuisioner kepada bagian pengadaan. Selanjutnya akan dilakukan perhitungan matriks perbandingan berpasangan untuk melakukan uji konsistensi kriteria, subkriteria dan alternatif. Nilai CR yang diperoleh dari uji konsistensi kurang dari 0,1 sehingga disimpulkan penilaian pada kuisioner telah konsisten[3].

Tabel 1 Hasil perhitungan bobot kriteria dan subkriteria F-AHP

\begin{tabular}{|c|c|c|c|}
\hline Kriteria & $\begin{array}{c}\text { Bobot } \\
\text { Kriteria }\end{array}$ & Subkriteria & $\begin{array}{c}\text { Bobot } \\
\text { Subkriteria }\end{array}$ \\
\hline \multirow[t]{2}{*}{ Harga } & 0,3342 & Harga/kg & 0,1899 \\
\hline & & Diskon & 0,1442 \\
\hline \multirow[t]{3}{*}{ Kualitas } & 0,2875 & Tingkat kekeringan & 0,1415 \\
\hline & & Warna & 0,054 \\
\hline & & Kemasan & 0,0919 \\
\hline \multirow[t]{2}{*}{ Kuantitas } & 0,2351 & Kemampuan pasok & 0,1175 \\
\hline & & Stabilitas ketersediaan & 0,1175 \\
\hline \multirow[t]{3}{*}{ Fleksibilitas } & 0,0269 & Perubahan jumlah pemesanan & 0,0075 \\
\hline & & Perubahan waktu antar & 0,0035 \\
\hline & & Waktu pembayaran & 0,0158 \\
\hline \multirow[t]{3}{*}{ Servis } & 0,116 & Kemudahan mendapatkan informasi & 0,0435 \\
\hline & & Respon komplain & 0,0435 \\
\hline & & Garansi dan klaim cacat & 0,0289 \\
\hline
\end{tabular}

Setelah penilaian konsisten, maka akan dilanjutkan dengan pengolahan F-AHP. Hasil dari pengolahan F-AHP diperoleh bobot kriteria dan subkriteria seperti pada tabel 1. Berdasarkan tabel 1 dapat dilihat bahwa bobot terbesar terdapat pada kriteria harga yaitu dengan bobot sebesar 0,3342. Prioritas kedua adalah kriteria kualitas dengan bobot sebesar 0,2875 dan prioritas ketiga adalah kapasitas dengan bobot sebesar 0,2351. Kriteria harga dianggap penting karena harga dipengaruhi oleh kualitas dan ketersediaan, serta harga yang terlalu tinggi dapat mengakibatkan pembengkakan biaya

Pada subkriteria diambil top 7 prioritas berdasarkan bobot terbesar. Adapun top 7 yang menjadi prioritas pada subkriteria anatara lain harga, diskon, tingkat kekeringan, kemampuan pasok, stabilitas ketersediaan, warna dan kemasan. Subkriteria diskon dianggap penting karena diskon yang dimaksud disini adalah tingkat keseringan pemberian diskon dan seberapa besar diskon yang diberikan per-kilogramnya. Semakin sering dan besar diskon yang diberikan maka akan dapat meminimalkan biaya pembelian asam jawa per-kilogramnya. 
Pada kriteria kualitas, subkriteria tingkat kekeringan memiliki bobot paling besar dari subkriteria warna dan kemasan yaitu dengan bobot sebesar 0,1415 . Hal itu dikarenakan tingkat kekeringan asam jawa yang menjadi faktor utama apakah asam itu tahan lama atau cepat rusak. Pada kriteria kapasitas, subkriteria kemampuan pasok dan stabilitas ketersediaan memeiliki bobot yang sama besar yaitu 0,1175.

Pengolahan bobot supllier dengan F-AHP dilakukan dengan cara membandingkan kinerja masing-masing supplier pada masing-masing subkriteria[8]. Pengolahan tersebut dilakukan dengan cara yang sama seperti pengolahan F-AHP kriteria dan subkriteria[9]. Hasil dari pengolahan F-AHP untuk alternatif supplier dapat dilihat seperti tabel 2 .

Tabel 2 Hasil perhitungan bobot supplier

\begin{tabular}{cccc}
\hline No. & Pemasok & Bobot & Ranking \\
\hline 1 & Toncan & 0,2935 & 1 \\
2 & Bahruki & 0,2815 & 2 \\
3 & Menten & 0,2167 & 3 \\
4 & UD Ikah & 0,2076 & 4 \\
\hline
\end{tabular}

Dari tabel 2. Dapat diketahui supplier dengan ranking 1 adalah Toncan dengan bobot sebesar 0,2935, raning 2 adalah Bahruki dengan bobot sebesar 0,2815, ranking 3 adalah Menten dengan bobot sebesar 0,2167 dan terakhir adalah UD Ikah dengan bobot sebesar 0,2076.

Kebutuhan pemesanan asam jawa pada bulan desember 2015 - februari 2016 adalah sebesar 23 ton, 20 ton dan 16,5 ton. Untuk memenuhi kebutuhan tersebut tidak bisa dengan hanya memesan pada satu supplier dikarenakan kemampuan memasok supplier paling besar hanya sampai 9 ton perbulannya, sehinnga terdapat kendala yang berhubungan dengan kemampuan memasok dari supplier. Oleh karena itu proses pemilihan supplier dilanjutnya dengan membuat formulasi untuk Goal Programing. Integrasi F-AHP dan Goal Programing yaitu dengan menggunakan bobot supplier hasil dari perhitungan F-AHP sebagai koefisien fungsi tujuan maksimasi bobot pemasok[10]. Dari hasil wawancara juga didapatkan budget atau batas maksimal biaya pembelian perbulannya sebesar Rp 130.000.000-

Formulasi model Goal Programing untuk pemilihan supplier dan alokasi order pada bulan desember 2015 dilakukan dengan mendefenisikan variabel keputusan, kendala yang berupa tujuan, kendala yang menjadi pembatas permsalahan dan tujuan yang ingin dicapai.

\section{Variabel Keputusan}

Xij : Kuantitas order untuk pemasok-i pada priode-j

Ujt : pencapaian dibawah target dari goal ke-j pada priode ke-t

Ejt : pencapaian diatas target dari goal ke-j pada priode ke-t

\section{Fungsi Kendala}

Kendala-kendala yang menjadi pembatas dalam pemilihan ini adalah pembatas permintaan (demand) dan kemampuan memasok supplier pada bulan desember 2015 . Adapun kendala tersebut sebagai berikut:

$\mathrm{S} 1 \leq 9000$

$\mathrm{S} 2 \leq 6000$

S3 $\leq 8000$ 
$\mathrm{S} 4 \leq 9000$

$\mathrm{S} 1+\mathrm{S} 2+\mathrm{S} 3+\mathrm{S} 4 \leq 23000$

Permbatas 12 sampai 15 memastikan bahwa kuantitas pembelian dari supplier tidak boleh melebihi kapasitas pasok perbulannya. Sebagai contoh pembatas 12 merupakan batas pemesanan asam jawa kepada supplier ke-1 yaitu Bahruki tidak boleh melebihi 9000 kilogram dan sebagainya. Sedangkan pembatas 16 merupakan batasan total pemesanan pada bulan desember 2015 tidak boleh melebihi 23000 kilogram.

Selanjutnya adalah formulasi untuk fungsi tujuan, adapun fungsi tujuan pertama adalah minimasi biaya pembelian. Persamaan 17 menunjukkan soft constraint yang berhubungan dengan biaya pembelian dengan menambahkan variabel penyimpangan/deviasi $\mathrm{U}$ dan $\mathrm{E}$ untuk melihat apakah pencapaian tujuan dibawah atau diatas target maksimal total biaya pembelian sebesar Rp 130.000.000-. tujuan kedua yaitu maksimasi bobot pemasok sebagaimana juga menambahkan variabel penyimpangan/deviasi seperti pada persamaan 18, dimana nilai sebelah kanan pada persamaan adalah value pembelian hasil dari generate alokasi order maksimasi bobot pemasok.. Persamaan 19 menunjukkan tujuan ketiga yaitu minimasi prosentase cacat juga menambahkan variabel penyimpangan/deviasi. Nilai sebelah kanan pada persamaan 19 merupakan batas maksimal total prosentase cacat yang ditetapkan oleh perusahaan dikalikan total permintaan pada bulan desember.

$5300 \mathrm{X}_{11}+6000 \mathrm{X}_{21}+5500 \mathrm{X}_{31}+5500 \mathrm{X}_{41}+\mathrm{U}_{11}-\mathrm{E}_{11} \leq 130000000$

$0,2840 \mathrm{X}_{11}+0,3067 \mathrm{X}_{21}+0,1997 \mathrm{X}_{31}+0,2089 \mathrm{X}_{41}+\mathrm{U}_{21}-\mathrm{E}_{21}=6,028$

$0,04 \mathrm{X}_{11}+0,02 \mathrm{X}_{21}+0,04 \mathrm{X}_{31}+0,03 \mathrm{X}_{41}+\mathrm{U}_{31}-\mathrm{E}_{31}=0,04 * 23000$

\section{Fungsi Tujuan}

Prioritas fungsi tujuan yang ingin dicapai adalah meminimalkan biaya pembelian, maksimasi bobot pemasok dan minimasi prosentase cacat, sehingga nantinya akan dapat mengurangi pembengkakan biaya total pembelian. Pada prioritas fungsi tujuan minimasi biaya pembelian dan minimasi total prosentase cacat diharapkan nilai penyimpangan diatas target (E) harus diminimalkan, sedangkan untuk fungsi tujuan maksimasi bobot pemasok diharapkan nilai penyimpangan dibawah target (U) harus dimaksimal. Selanjutnya fungsi tujuan akan dinyatakan seperti persamaan berikut:

Min : $\mathrm{E}_{11}+\mathrm{U}_{21}+\mathrm{E}_{31}$

Penyelesaian model Goal Programing untuk pemilihan supplier asam jawa pada bulan desember 2015 dengan menggunakan bantuan software LINDO 6.1 dan hasil running-nya ditunjukkan pada tabel 3. Dari hasil running diperoleh keputusan akhir pemilihan supplier yang akan memasok pada bulan desember 2015 yaitu Bahruki sebesar 9000 kilogram, Toncan sebesar 6000 kilogram dan Menten sebesar 8000 kilogram. Dari hasil running pada bulan desember juga diperoleh nilai penyimpangan/deviasi $\mathrm{U} 11=0, \mathrm{E} 11=0, \mathrm{U} 21=0, \mathrm{E} 21=6,022, \mathrm{U} 31=200$ dan $\mathrm{E} 31=0$ yang artinya ketiga prioritas tujuan sudah tercapai karena nilai penyimpangan E11, U21 dan E31 sama dengan 0. Nilai variabel E21=6,022 yang artinya alokasi order pada bulan desember memberikan tambahan bobot kepada pemasok terpilih sebesar 6,022. Sedangkan nilai variabel U31=200 yang artinya alokasi order pada bulan desember memberikan total order cacat lebih kecil sebesar 200kilogram dari target yang ditetapkan perusahaan yaitu 920kilogram.

Pemasok Bahruki adalah pemasok yang menawarkan harga/kg yang lebih rendah dari semua alternatif pemasok dan menempati bobot prioritas peringkat kedua sehingga pemasok Bahruki layak untuk dipilih menjadi pemasok asam jawa. Pemasok Toncan adalah pemasok dengan kualitas asam jawa lebih baik dari semua alternatif 
pemasok dan Toncan juga merupakan pemasok dengan bobot prioritas tertinggi sehingga layak untuk dipilih menjadi pemasok asam jawa. Dan terakhir Pemasok Menten lebih dipilih karena memiliki bobot prioritas lebih besar dari UD.Ikah dengan ranking ketiga, meskipun kedua pemasok menawarkan harga/kg yang sama.

Tabel 3 Hasil keputusan akhir pemilihan supplier asam jawa

\begin{tabular}{lcccc}
\hline Pemasok & $\begin{array}{c}\text { Bobot } \\
\text { Pemasok }\end{array}$ & Desember & Jlokasi order (kg) & \\
& 0,2815 & 9000 & 9000 & Februari \\
\hline Bahruki & 0,2935 & 6000 & 6000 & 9000 \\
Toncan & 0,2076 & - & - & 6000 \\
UD Ikah & 0,2167 & 8000 & 5500 & - \\
Menten & 23000 & 20000 & 1500 \\
Total Permintaan & 200 & 170 & 12500 \\
\multicolumn{2}{c}{ Total cacat } & 127.450 .000 & 110.950 .000 & 83.450 .000 \\
Total biaya (Rp) & 920 & 800 & 660 \\
Batas maks cacat & 130.000 .000 & 130.000 .000 & 130.000 .000 \\
\multicolumn{2}{c}{ Batas maks biaya } & & & \\
\hline
\end{tabular}

Dengan formulasi Goal Programing pada bulan desember 2015 sebagai berikut:

Min : $\mathrm{E}_{11}+\mathrm{U}_{21}+\mathrm{E}_{31}$

Subject to :

$\mathrm{S} 1 \leq 9000$

$\mathrm{S} 2 \leq 6000$

$\mathrm{S} 3 \leq 8000$

$\mathrm{S} 4 \leq 9000$

$\mathrm{S} 1+\mathrm{S} 2+\mathrm{S} 3+\mathrm{S} 4 \leq 23000$

$5300 \mathrm{X}_{11}+6000 \mathrm{X}_{21}+5500 \mathrm{X}_{31}+5500 \mathrm{X}_{41}+\mathrm{U}_{11}-\mathrm{E}_{11} \leq 130000000$

$0,2840 \mathrm{X}_{11}+0,3067 \mathrm{X}_{21}+0,1997 \mathrm{X}_{31}+0,2089 \mathrm{X}_{41}+\mathrm{U}_{21}-\mathrm{E}_{21}=6,028$

$0,04 \mathrm{X}_{11}+0,02 \mathrm{X}_{21}+0,04 \mathrm{X}_{31}+0,03 \mathrm{X}_{41}+\mathrm{U}_{31}-\mathrm{E}_{31}=0,04 * 230 \quad 00$

\section{Simpulan}

Kriteria yang dipertimbangkan oleh CV.MANDIRI dalam pemilihan pemasok terdiri dari 5 kriteria dengan 13 subkriteria. Adapun kriteria yang dipertimbangkan antara lain adalah harga, kualitas, kapasitas, fleksibilitas dan servis. Sedangkan untuk subkriteria antara lain harga/kg, diskon, tingkat kekeringan, warna, kemasan, kemampuan memasok, stabilitas ketersediaan, perubahan jumlah pemesanan, perubahan waktu kirim, waktu pembayaran, kemudahan mendapatkan informasi, respon komplain dan garansi dan klaim produk cacat.

Untuk keputusan akhir alternatif supplier terpilih yang akan memasok pada bulan desember 2015 - februari 2016 pertama adalah Toncan dengan bobot 0,2935 dengan jumlah pemesanan sebesar 6 ton perbulannya. Kedua adalah Bahruki dengan bobot 0,2815 dengan jumlah pemesanan sebesar 9 ton perbulannya. Dan yang terakhir 
Menter dengan bobot 0,2167 dengan jumlah pemesanan sebesar 8; 5,5 dan 1,5 ton selama 3 bulan.

\section{Referensi}

[1] T. Malikah, A. W. Kurniawan, S. Si, and M. Kom, "Implementasi Fuzzy Analytical Hierarchy Process (Fahp) Untuk Proses Seleksi Usulan Kegiatan Pnpm Mandiri Perdesaan," ed: Skripsi. Semarang: FIK, Teknik Informatika, Universitas Dian Nuswantoro, 2015.

[2] X. Ouyang, F. Guo, D. Shan, H. Yu, and J. Wang, "Development of the integrated fuzzy analytical hierarchy process with multidimensional scaling in selection of natural wastewater treatment alternatives," Ecological Engineering, vol. 74, pp. 438-447, 2015.

[3] S. A. Rahaman, S. A. Ajeez, S. Aruchamy, and R. Jegankumar, "Prioritization of Sub Watershed Based on Morphometric Characteristics Using Fuzzy Analytical Hierarchy Process and Geographical Information System-A Study of Kallar Watershed, Tamil Nadu," Aquatic Procedia, vol. 4, pp. 1322-1330, 2015.

[4] S. Chamoli, "Hybrid FAHP (fuzzy analytical hierarchy process)-FTOPSIS (fuzzy technique for order preference by similarity of an ideal solution) approach for performance evaluation of the $\mathrm{V}$ down perforated baffle roughened rectangular channel," Energy, vol. 84, pp. 432-442, 2015.

[5] J. Tan, K. Y. Low, N. M. N. Sulaiman, R. R. Tan, and M. A. B. Promentilla, "Fuzzy analytical hierarchy process (AHP) for multi-criteria selection in drying and harvesting process of microalgae system," Chem Eng Trans, vol. 45, pp. 829834, 2015.

[6] L. Shen, K. Govindan, and M. Shankar, "Evaluation of barriers of corporate social responsibility using an analytical hierarchy process under a fuzzy environmentA textile case," Sustainability, vol. 7, pp. 3493-3514, 2015.

[7] F. ATAOLLAHI, M. Bahrami, M. Abesi, F. Mobasheri, and S. Khani, "A Goal Programming Model For Reallocation Of Inpatient Beds In Educational Shahid Mohamadi Educational Hospital Of Bandar Abbas, Iran," 2014.

[8] B. T. Sivrikaya, A. Kaya, M. Dursun, and F. Çebi, "Fuzzy AHP-goal programming approach for a supplier selection problem," Research in Logistics \& Production, vol. 5, pp. 271--285, 2015.

[9] M. Dabbaghian, K. Hewage, B. Reza, K. Culver, and R. Sadiq, "Sustainability performance assessment of green roof systems using fuzzy-analytical hierarchy process (FAHP)," International Journal of Sustainable Building Technology and Urban Development, vol. 5, pp. 260-276, 2014.

[10] P. Sheela and M. R. Murthy, "The Use Of Fuzzy Analytical Hierarchy Process (Fahp) Model For The Primary Screening Of Business Opportunity, In The Process Of Entrepreneurial Activity," International Journal of Marketing, Financial Services and Management Research, vol. 4, 2015. 